\title{
Prediction of Flowering Occurrence in Faba Bean (Vicia faba L.)
}

\author{
Hosein AJAM NOROUZI ${ }^{1}$, Farshid VAZIN² \\ ${ }^{1}$ Islamic Azad University, Gorgan branch, Gorgan, Iran; ajamnorozei@yahoo.com \\ ${ }^{2}$ Islamic Azad University, Gonabad branch, Gonabad, Iran; farshidvazin@gmail.com ('corresponding author)
}

\begin{abstract}
This study is about quantifying response flowering rate to temperature and photoperiod. Results indicated that the response of faba bean flowering rate is described by beta-segmented ('Barekat,', Saraziri', 'Eraghi') and beta-quadratic functions ('Gavi'). The use of quantitative data about the response of phonological development to temperature and photoperiod in faba bean is limited. This study was undertaken to examine phonological development of four faba bean cultivars ('Barekat,' 'Saraziri', 'Eraghi', 'Gavi') under 11 sowing dates. The experiment was conducted in Gorgan during 2005-2006. Various response functions were evaluated for unctions, cardinal temperatures (base, optimum, and ceiling) for flowering and ceiling photoperiod (the photoperiod below which flowering rate begins to decrease), and photoperiod sensitivity coefficient (slope of the function in response to photoperiod) for flowering rate were determined. 'Barekat,' 'Saraziri', and 'Eraghi' cultivars showed a qualitative long-day plant (LDP) response to photoperiod, and progress toward flowering stopped when photoperiod decreased about $10 \mathrm{~h}$ per day. However, 'Gavi' cultivar showed a quantitative long-day plant (LDP) response to photoperiod. Ceiling photoperiod estimated by beta-segmented function for 'Barekat,' 'Saraziri', and 'Eraghi' cultivars were between 14.5 to $16.1 \mathrm{~h}$ and by beta-quadratic function for 'Gavi' cultivar was 15.3.
\end{abstract}

Keywords: faba bean, flowering, modeling

\section{Introduction}

The most important phonological stage is the flowering stage where plant transmission from the processes changes with the plant growth. The quantification of the exact phonological growth in all simulation models of the plants is necessary. The influential parameters on phonology of each cultivar can be distinct and unique (Farre et al., 2002). The predictive ability of reproductive and vegetative growth stage as a function from particular environmental variable is a basic requirement for crop models (Grimm et al., 1994). Predicted models of the phonological growth according to reaction description is stable to the environmental factors (Hammer et al., 1996). For model usage in wider range from cultivation dates and latitude are used and photoperiod effect in addition to thermo time effect are considered. The models application and development for the exact explanation of phonological growth reaction to temperature and photoperiod is under farm situation (Birch et al., 1998). There are several models for quantifying these reactions. However, often in places with different environment condition, these models show unsuccessful predicts. A reason for such behaviors is that the used parameter in the model is estimated from a series of limited data. To obtain more estimates of the parameters for predicting phonological stages, the used data must include wide range of places and/or cultivation dates (Grimm et al., 1993; Soltani et al., 2006). Ellis et al. (1990) reported that ceiling photoperiod which delays the flowering of dif- ferent bean cultivars is more than eighteen daylight hours. Besides, it is determined that the ceiling photoperiod (the longest photoperiod that causes the maximum delay in flowering) for different bean genotypes is not the same. In most genotypes, the ceiling photoperiod is more than 10 to 16 daylight hours (Roberts et al., 2002). Except in bean cultivars that flower early, flower initiation in other bean cultivars is actuated with high temperature and the length of day. In the other, long days are needed for complete flower development. When the temperature is higher than 14 degrees centigrade and especially higher than 23, an inhibition state happens in the bean's flower initiation. Temperatures of lower than 10 can be influential in the bean's flower initiation. The plant also can receive such low temperatures during fetal period on the basic plant (Evans, 1959). Most bean genotypes are sensitive to the photoperiod and require long days before they can flower (Hadle et al., 1984). Evans (1959) reported that the required temperature for the beginning of sexual reproduction for a winter type is 22 degrees centigrade, and that for another winter type is 17 degrees centigrade. Beans are long-day plants. The necessary range of the photoperiod for flowering of the spring and winter bean cultivars is 14 to 24 hours (Stutzel, 1995b). Turpin et al. (2002) reported basic and ceiling photoperiods for flowering period until the bean's seed formation are 12.5 and 14 hours, respectively. Also, these two photoperiods from the beginning stage until the formation of the bean's seed were reported at 12.5 and 14 hours, respectively. For stages after seed fill- 
ing of the bean-from seed formation to seed maturation and from seed maturation to harvesting, only the temperature is effective in growth completion. Ellis et al. (1992) reported a basic, optimum, and ceiling temperatures of $7,30.5$, and 40 degrees centigrade, respectively, for steps between sprouting and maturity of mungbean. Yin et al. (1997) reported that the basic, optimum, and ceiling temperatures for the steps between sprouting till peanut maturity are 9, 29, and 39 degrees centigrade. The quality perception of the bean's phonological growth reaction to the photoperiod and temperature allows the formation of a model for the time predicting the different possible growth stages. Having access to such information by doing farm survey will provide the possibility of determining the suitable sowing date for different cultivars. Cardinal temperature (basic, optimum, and ceiling) and photoperiod's parameters (ceiling photoperiod, optimum photoperiod, sensitivity coefficient to photoperiod, and the slope of growth rate in front of the photoperiod) are important in using these models. Because there are no available detailed information about bean's reaction (Iranian cultivars) to the temperature and photoperiod, this survey was done with the following aims: to compare the different models in terms of the flowering rate reaction of different bean cultivars to the temperature and the photoperiod in the farm condition and to determine the cardinal temperature and related parameters in the reaction to the photoperiod (ceiling daylight and coefficient to the photoperiod) for the flowering stage of different bean cultivars in the farm condition and its variety survey.

\section{Material and methods}

This experiment was conducted within 2005 and 2006 in Gorgan agriculture research with northern latitude $39^{\circ} 45^{\prime}$ eastern longitude $54^{\circ} 25^{\prime}$ and 5.5 meters high above sea level in silty clay loam soil. The considered land was plowed after wheat harvest in 2004. The experiment included 11 sowing dates: 4 August, 1 September, 2 October, 31 October, 30 November, and 31 December in 2005 and 31 January, 1 March, 30 March, 28 April, and 28 May in 2006. In each sowing date, the experiment was performed in a design of randomized complete blocks with 4 replication, each block containing 4 bean cultivars from different regions: 'Barekat' (the main cultivar in Gholestan province), 'Saraziri' (the main cultivar in Khozestan province), 'Gavi' (the main cultivar in Lorestan province), and 'Eraghi' (the main cultivar in Gholestan province); each grain weighs $1320,1250,1200$, and 520 grams, respectively. Every plot included 3 sowing lines with an interval of 4 meters and 60 centimeters. In this study, 10 bushes (brush and brush wood) were selected randomly in order of the flowering stage record for each sowing date in each plot and were marked with a string. When $50 \%$ of these marked bushes contain at least one flower, the flowering date of the plot is recorded (Fehr and Caviness, 1980). The record of pod be- ginning stage $\left(\mathrm{R}_{3}\right.$; when $50 \%$ of the marked bushes in 4 or greater countable nodes of the main stem yellow, the seed length reaches to 3 millimeters), the beginning maturation or physiological maturation $(R$, when $50 \%$ of marked bushes have at least one yellow pod in every place of the bush) and complete maturation ( $R_{8}$, when most of $90 \%$ of the pods change into ripe pod color, yellow or brown) were done on the same 10 bushes that were selected for recording of flowering stage. For calculating the beginning and end of the photoperiod, a time was considered when the sun is 6 degrees under the horizon. Sunlight intensity before the sunrise and after the sunset is enough to affect the plant's reaction to the photoperiod (Fehr and Caviness, 1980). Then, the opposite of the required time was calculated for reaching the $50 \%$ flowering rate. In calculating of growth rate from sprouting to flowering as a function of temperature and photoperiod, this equation was used (Soltani et al., 2006a).

$$
R=R_{\max } f(T) f(P P)
$$

In this equation, $\mathrm{R}$ is the growth rate; $R_{\max }$ is the growth rate in ceiling temperature and photoperiod (maximum growth rate), $f(T)$ is the temperature function, and $f(P P)$ is the photoperiodic function. The opposite of $R_{\text {max }}$ (shown with $f_{0}$ ) shows the minimum number of days required from sprouting to flowering stage. $f(P P)$ and $f(T)$ are calculated for each day separately, and their amount varies between zero and 1 . When $f(T)$ and $f(P P)$ are equal to one, the flowering happens during the minimum time (or maximum rate). When the growth rate for each day and its total amount are calculated and are equal to one, it is predicted that flowering has occurred during this time; this means that:

$$
\sum f(T) f(P P)=1 / R_{\max }=f_{0}
$$

Used temperature functions include the following: 1. Piecewise function (Soltani et al., 2006a)

$$
\begin{array}{lll}
f(T)=\frac{\left(T-T_{b}\right)}{\left(T_{o}-T_{b}\right)} & \text { if } & T_{b}<T \leq T_{o} \\
f(T)=\frac{\left(T_{c}-T\right)}{\left(T_{c}-T_{o}\right)} & \text { if } & T_{o}<T<T_{c} \\
f(T)=0 & \text { if } & T \leq T_{b} \text { or } T \geq T_{c}
\end{array}
$$

2. $\beta$-function (Soltani et al., 2006a)

$f(T)=\left[\left(\frac{T-T_{b}}{T_{o}-T_{b}} \times \frac{T_{c}-T}{T_{c}-T_{b}}\right)^{\frac{T_{c}-T_{o}}{T_{o}-T_{b}}}\right]^{\alpha}$ if $\quad T>T_{b} \quad T<T_{c}$

$f(T)=0 \quad$ if $\quad T \leq T_{b}$ or $T \leq T_{c}$

3. Quadratic function (Soltani et al., 2006a)

$$
f(T)=\left[\left(T-T_{b}\right) \times\left(T_{c}-T\right) \times\left(\frac{T_{c}-T_{b}}{2}\right)^{-2}\right]
$$


200

4. Curves function (Soltani et al., 2006a)

$\left.f(T)=\left[\left(1 /\left(T_{o}-T_{b}\right) \times\left(T_{c}-T_{o}\right)^{\left(\frac{T_{c}-T_{o}}{T_{o}-T_{b}}\right)}\right)\right] \times\left(T-T_{b}\right) \times\left(T_{c}-T\right)^{\left(\frac{T_{c}-T_{o}}{T_{o}-T_{b}}\right)}\right]$

5. Saw tooth function (Soltani et al., 2006a)

$$
\begin{array}{lll}
f(T)=\frac{\left(T-T_{b}\right)}{\left(T_{01}-T_{b}\right)} & \text { if } & T_{b}<T<T_{01} \\
f(T)=\frac{\left(T_{c}-T\right)}{\left(T_{c}-T_{02}\right)} & \text { if } & T_{02}<T<T_{c} \\
f(T)=1 & \text { if } & T_{01} \leq T \leq T_{02} \\
f(T)=0 & \text { if } & T \leq T_{b} \text { or } T \geq T_{c}
\end{array}
$$

Used photoperiod functions include the following (Soltani et al., 2006a, b; Roberts et al., 2002):
1. Piecewise $f(P P)=[1-(P P-C P P) \times P P S e n]$
2. Quadratic
3. Negative exponent $f(P P)=[1-P P S e n \times(C P P-P P) 2$ $f(P P)=[\exp (-P P \operatorname{Sen} \times(c p p-p p)]$

In this functions, $T$ is the average weather temperature, $T_{b}$ is the basic temperature, $T_{0}$ is the optimum temperature, $T_{0 l}$ is the minimum optimum temperature (for Saw tooth function), and $T_{02}$ is the form parameter for $\beta$-function that determines the function curve. Because the temperature often is not higher than 35 degrees at the time of using these mentioned functions, $T$ in 35 degrees was considered fixed. $P P$ is the photoperiod (hours in the day), $C P P$ is the ceiling photoperiod during shorter days from which growth rate is decreased, and PPSen is the sensitivity coefficient to the photoperiod. In this study, five temperature functions in combination with three photoperiod functions (composed of 15 models) was used for describing flowering rate to temperature and photoperiod. For estimating the parameters of each optimization, the software model DEVEL (Hammer et al., 1996), improved by Soltani et al. (2006b), was used in the monitoring of the daily maximum and minimum temperatures, photoperiod, and observed dates of sprouting and flowering. DEVEL uses the optimization simplex method and contains a set of 8 cases for temperature and photoperiodic functions that are changeable from linear reaction to logistic and can be used separately or in a compound form for the evaluation of independent and interaction effects of temperature and photoperiod. The user selects a function for describing the reaction and enters the first evaluation of the parameters and their range; then, DEVEL, for a repeated optimization that decreases the total residual sum of squares $(S S E=\Sigma[(\Sigma R-1) 2])$, is used and earns the final estimations of the parameters. The user repeats the process with other functions and chooses a function that statistically has the best fit for the reaction to the temperature and photoperiod. DEVEL also calculates the smallest and biggest parameter estimation which leads to a maximum
SSE of 10 percent from the final minimum amount (Soltani et al., 2006b). DEVEL includes algorithms for profiling the parameters that omit the oblique from the parameter estimations, and the process accuracy increases the parameter selection (Soltani et al., 2006b). Criterions of root mean square error (RMSE), $R$ square coefficient $\left(R_{2}\right)$, simple linear regression coefficients ( $\mathrm{a}, \mathrm{b})$, and correlation coefficient $(r)$ were used for choosing the best model. In comparing the amounts of calculated parameters through the different models of the bean cultivars, the standard error (SE) was used according to the concept of certainty limit of $95 \%$ (Soltani, 1998).

\section{Results and discussion}

\section{The number of days to pudding $\left(R_{3}\right)$}

The impact of sowing date and cultivar on the number of days to pudding was significant (Tab. 1). The period of planting to pudding was $179.2,184.3,58.4$, and 61.6 days for sowing dates of August 2005, September 2005, April 2006, and May 2006, respectively. The number of days to pudding for 'Barekat', 'Saraziri', and 'Eraghi' cultivars (110 days) was shorter than that for 'Gavi' cultivar (127 days) (Tab. 2). Stutzel (1995a) reported that the necessary photoperiod for bean flowering is the reason for the difference among the sowing dates because the photoperiod range for beans is different, and thus, the flowering time in different cultivars is different.

It seems that the length of day and the other factors that delay the flowering induction in various cultivars also are effective on pod formation. Miralles (2001) reported that soybean and sunflower in the initial stages until pollination and from pollination until physiological maturation show independent reactions to temperature, and the duration of these stages increases with average temperature decrease.

Tab. 1. Analysis of variance for the development stage of faba bean (Vicia faba L.) based on experiments and combined analysis

\begin{tabular}{cccccc}
\hline SOV & df & DUR $_{3}$ & DUR $_{5}$ & DUR $_{7}$ & DUR $_{8}$ \\
\hline Sowing date & 9 & $\cdots 349406$ & 464584 & 349406 & $536195^{\cdots}$ \\
Error(a) & 30 & 6068.10 & 463.00 & 60.56 & 69.38 \\
$\begin{array}{c}\text { Genotype } \\
3\end{array}$ & $8591^{\cdots}$ & $4484.90 \cdots$ & $490.10^{\cdots \cdots}$ & 368.75 \\
$\begin{array}{c}\text { Sowing date } \\
\text { genotype }\end{array}$ & 27 & 8764 & $1460.70 \cdots$ & $370.50 \cdots$ & $332.63 \cdots$ \\
Error(b) & 90 & 13424.2 & 598.50 & 171.69 & 131.63 \\
\hline
\end{tabular}

${ }^{*},{ }^{* *},{ }^{* * *}$ Significant at the $5 \%, 1 \%$, and $0.1 \%$ levels of probability, respectively; $\mathrm{R} 3$ = number of days until pudding, $\mathrm{DUR}_{5}=$ number of days until seed filling; $\mathrm{DUR}_{7}=$ number of days until physiological maturation, $\mathrm{DUR}_{8}=$ number of days until complete maturation

\section{The number of days to seed filling $\left(R_{5}\right)$}

The impact of sowing date and the cultivar, as well as their interaction, on the number of days to seed filling was significant (Tab. 1). The number of days to seed filling 
Tab. 2. Mean comparisons of the development stages for the four faba bean (Vicia faba L.) cultivars in different sowing dates

\begin{tabular}{|c|c|c|c|c|c|c|c|c|c|c|c|c|c|c|c|c|}
\hline \multirow[b]{2}{*}{ Sowing dates } & \multicolumn{4}{|c|}{ 'Barekat' } & \multicolumn{4}{|c|}{ 'Saraziri' } & \multicolumn{4}{|c|}{ 'Eraghi' } & \multicolumn{4}{|c|}{ 'Gavi' } \\
\hline & $\mathrm{R}_{3}$ & $\mathrm{R}_{s}$ & $\mathrm{R}_{7}$ & $\mathrm{R}_{8}$ & $\mathrm{R}_{3}$ & $R_{5}$ & $\mathrm{R}_{7}$ & $\mathrm{R}_{8}$ & $\mathrm{R}_{3}$ & $\mathrm{R}_{5}$ & $\mathrm{R}_{7}$ & $\mathrm{R}_{8}$ & $\mathrm{R}_{3}$ & $R_{5}$ & $\mathrm{R}_{7}$ & $\mathrm{R}_{8}$ \\
\hline \multicolumn{17}{|c|}{2005} \\
\hline 4 August & $165 a$ & $124.2 \mathrm{c}$ & $248 b$ & $256 \mathrm{~b}$ & $163.7 \mathrm{~b}$ & $124.5 \mathrm{bc}$ & $248 b$ & $256 \mathrm{~b}$ & $161.7 b$ & $125.6 b$ & $248 \mathrm{a}$ & $256 b$ & $226.5 a$ & $136.9 \mathrm{a}$ & $256.5 \mathrm{a}$ & $263.2 \mathrm{a}$ \\
\hline 1 September & $179.2 \mathrm{~b}$ & $193.7 \mathrm{~b}$ & $220 \mathrm{~b}$ & $232 b$ & $176.7 \mathrm{c}$ & $192 \mathrm{~b}$ & $220 \mathrm{~b}$ & $232 b$ & $179.2 \mathrm{~b}$ & $194 b$ & $220 \mathrm{~b}$ & $232 b$ & $202.2 \mathrm{a}$ & $213 a$ & $225 \mathrm{a}$ & $234.2 \mathrm{a}$ \\
\hline 2 October & $156.2 \mathrm{a}$ & $162.2 \mathrm{~b}$ & $195.5 b$ & $202 b$ & $156 \mathrm{~b}$ & $162 b$ & $195 b$ & $202.5 b$ & $157.7 \mathrm{~b}$ & $168 \mathrm{~b}$ & $195 \mathrm{~b}$ & $202.5 b$ & $180 \mathrm{a}$ & $188 \mathrm{a}$ & $204 a$ & $210 a$ \\
\hline 31 October & $131 b$ & $151.7 \mathrm{a}$ & $174 \mathrm{~b}$ & $179 \mathrm{~b}$ & $135.2 \mathrm{~b}$ & $157.5 \mathrm{a}$ & $173 b$ & $179 \mathrm{~b}$ & $132.7 \mathrm{~b}$ & $155 a$ & $173 b$ & $180 \mathrm{ab}$ & $150 \mathrm{a}$ & $157.7 \mathrm{a}$ & $177.2 \mathrm{a}$ & $182 a$ \\
\hline 30 November & $117 \mathrm{~b}$ & $126.7 \mathrm{~b}$ & $156.2 \mathrm{~b}$ & $161 \mathrm{a}$ & $117 \mathrm{~b}$ & $127.2 \mathrm{~b}$ & $156 \mathrm{~b}$ & $161.5 \mathrm{a}$ & $117 \mathrm{~b}$ & $127.7 \mathrm{~b}$ & $156 \mathrm{~b}$ & $161 \mathrm{a}$ & $130 \mathrm{a}$ & $142 a$ & $160.7 \mathrm{ab}$ & $162.7 \mathrm{a}$ \\
\hline 31 December & $94.5 \mathrm{c}$ & $102.5 \mathrm{~b}$ & $127 \mathrm{~b}$ & $130.7 \mathrm{~b}$ & $94.5 \mathrm{c}$ & $102.2 \mathrm{~b}$ & $127.7 \mathrm{~b}$ & $130.5 \mathrm{~b}$ & $96.2 \mathrm{~b}$ & $103.7 \mathrm{~b}$ & $127.7 \mathrm{~b}$ & $131.2 \mathrm{~b}$ & $99 \mathrm{a}$ & $112.5 \mathrm{a}$ & $131.7 \mathrm{a}$ & $134.2 \mathrm{a}$ \\
\hline \multicolumn{17}{|c|}{2006} \\
\hline 31 January & $73 b$ & $78.7 \mathrm{~b}$ & $104 a$ & $107 \mathrm{a}$ & $73 \mathrm{~b}$ & $78.5 b$ & $104 a$ & $107 \mathrm{a}$ & $73 b$ & $79.5 \mathrm{~b}$ & $104 a$ & $107 \mathrm{a}$ & $79 \mathrm{a}$ & $85.2 \mathrm{a}$ & $104 a$ & $107 \mathrm{a}$ \\
\hline 1 March & $67 \mathrm{~b}$ & $74.7 \mathrm{~b}$ & $93 a b$ & $102.7 \mathrm{~b}$ & $64.2 \mathrm{~b}$ & $72.2 \mathrm{~b}$ & $96.2 \mathrm{a}$ & $103.2 \mathrm{~b}$ & $69.2 \mathrm{~b}$ & $74.5 \mathrm{~b}$ & $96.2 \mathrm{a}$ & $105 b$ & $77 a$ & $86.2 \mathrm{a}$ & $95 \mathrm{ab}$ & $108 a$ \\
\hline 30 March & $60.5 b$ & $67.2 \mathrm{~b}$ & $87.5 \mathrm{a}$ & $94.7 \mathrm{ab}$ & $60 \mathrm{~b}$ & $69.2 \mathrm{ab}$ & $87.5 \mathrm{a}$ & $95 \mathrm{a}$ & $61.5 b$ & $68.5 \mathrm{ab}$ & $87.5 a$ & $93.7 \mathrm{~b}$ & $64.7 \mathrm{a}$ & $71 \mathrm{a}$ & $85.2 b$ & $92.2 \mathrm{c}$ \\
\hline 28 April & $56 \mathrm{~b}$ & $65 \mathrm{~b}$ & $80 \mathrm{~b}$ & $83.7 \mathrm{c}$ & $58 \mathrm{~b}$ & $65 \mathrm{~b}$ & $80 \mathrm{a}$ & $84.5 \mathrm{~b}$ & $57.7 \mathrm{~b}$ & $65 \mathrm{~b}$ & $80 \mathrm{~b}$ & $84 b c$ & $62 \mathrm{a}$ & $78 \mathrm{a}$ & $86 a$ & $92 \mathrm{a}$ \\
\hline 28 May & -...-..- & ....... & -..-- & .....-. & ....... & ........- & ....... & .....-. & -...-... & -...... & ....... & -...-...- & ....... & -.....- & -...-...-. & -....- \\
\hline
\end{tabular}

The mean of the same letters in the $\% 5$ level for LSD test does not show the significant difference; $R_{3}=$ number of days until pudding; $R_{5}=$ number of days until seed filling; $\mathrm{R}_{\mathrm{r}}=$ number of days until physiological maturation; $\mathrm{R}_{\mathrm{8}}=$ number of day until complete maturation

for August 2010 sowing date was longer than April 2006 and May 2006 sowing dates (223 vs. 68 days). 'Gavi' cultivar with 136.95 days had the longest, and 'Barekat' and 'Saraziri' cultivars with 124 days had the shortest period of planting to seed filling (Tab. 2). Soltani (2006a) reported that the range of day length to the flowering in cultivars and sowing dates of the pea are different.

A part of this stage is affected by temperature. Duration until flowering and the number of days to pod formation increase when the length of day increases. Jame et al. (2004) reported that the duration of flowering stage until safflower maturation is not affected by sowing dates because, in any case, it is exposed to high temperature; however, when it is exposed to low temperature, their duration increases, so each of these development stages of safflower react to the temperature independently.

\section{The number of days to physiological maturity $\left(R_{7}\right)$}

The impact of sowing date and cultivar, as well as their interaction, on the number of days to seed filling was significant (Tab. 1). August 2005 sowing date with 250 days had the longest, and May 2005 sowing date with 81 days had the shortest period of planting to physiological maturity (Tab. 2). In 'Barekat', 'Saraziri', and 'Eraghi' cultivars, this stage occurred 148 days after planting, whereas this period for 'Gavi' cultivar reached the $\mathrm{R}_{7}$ stage after 153 days. This stage is under the effect of the temperature. The length of this stage is directly dependent to the number of days to flowering and pod formation stages. Khajehpoor (1998) reported with increasing temperature; the duration of development stage decreases because the required accumulative temperature of the plant is provided for completing the life cycle in a shorter time.

\section{The number of days until complete maturation $\left(R_{8}\right)$}

The impact of sowing date and cultivar, as well as their interaction, on the number of days to seed filling was significant (Tab. 1). August 2005 and May 2006 sowing dates had the longest and shortest duration, respectively, to complete maturity (257 vs. 86 days) (Tab. 2). 'Barekat', 'Saraziri', and 'Gavi' cultivars with 155 days had the shortest and 'Gavi' with 159 days had the longest duration to complete maturity. In the Gorgan region, from September, the photoperiod to first day of winter and temperature to the last day of winter decrease and consequently cause delay in flowering. In other hand, cultivated plants in spring, especially in June with longer photoperiod and higher temperature, were exposed to more rates of needed accumulative temperature and reached the flowering stage more rapidly.

\section{Comparison of the different models for quantifying the flowering rate's reaction to the temperature and the photoperiod}

$\beta$-Piecewise model for 'Barekat', 'Saraziri', and 'Eraghi', the better and final model, were selected because its root mean square deviation (RMSD) was low (9.35-11.66), the coefficient of variation (CV) was acceptable (16.92$20.17)$, the $R$ square $\left(R^{2}\right)$ was higher (0.83-0.95), and the correlation coefficient $(\mathrm{r})$ between the number of days until observed and predicted flowering stage was higher (0.9-0.93). So for predicting the phonological development of these cultivars, the $\beta$-piecewise model can be used (Tab. 3 and Fig. 1). The better model for predicting phonological development in 'Gavi' cultivar of $\beta$-negative exponent model was selected. Because, first, the RMSD and CV were 11.22 and 14.19 smaller, respectively, than the other models. Second, the amount of $R$ square $\left(R^{2}\right)$ and correlation coefficient $(r)$ were 0.89 and 0.97 bigger, respectively, than the other models (Tab. 4 and Fig. 1). So the $\beta$-negative exponent model for predicting phonological development of the 'Gavi' cultivar was selected as the better and final model. Different researchers have used different functions for describing temperature and photoperiod effects on development rate. From these equations, 
202

Tab. 3. Root mean square deviation (RMSD), variable coefficient $(\mathrm{CV})$, $\mathrm{R}$ square $\left(\mathrm{R}^{2}\right)$ for the different descriptive model relationship between the flowering rate with temperature and photoperiod in the four faba bean (Vicia faba L.) cultivars

\begin{tabular}{cccccccc}
\hline Temperature function & Cultivar & RMSD & CV & $\mathrm{R}^{2}$ & $\mathrm{a} \pm$ SE & $\mathrm{b} \pm$ SE & $\mathrm{r}$ \\
\hline \multirow{3}{*}{$\beta$} & 'Barekat' & 11.63 & 20.17 & 0.91 & $4.60 \pm 4.25$ & $0.91 \pm 0.07$ & 0.90 \\
& 'Saraziri' & 11.08 & 18.87 & 0.95 & $-2.36 \pm 4.13$ & $1.05 \pm 0.07$ & 0.93 \\
& 'Eraghi' & 9.35 & 16.92 & 0.83 & $5.87 \pm 3.67$ & $0.88 \pm 0.06$ & 0.91 \\
& 'Gavi' & 27.30 & 33.49 & 0.89 & $21.31^{*} \pm 7.72$ & $0.68^{*} \pm 0.07$ & 0.82 \\
& 'Barekat' & 23.42 & 37.31 & 0.56 & $12.27 \pm 8.55$ & $0.87 \pm 0.13$ & 0.71 \\
Piecewise & 'Saraziri' & 22.72 & 35.52 & 0.61 & $4.79 \pm 4.47$ & $1.02 \pm 0.13$ & 0.76 \\
& 'Eraghi' & 20.38 & 32.82 & 0.45 & $3.63 \pm 7.99$ & $1.04 \pm 0.13$ & 0.77 \\
& 'Gavi' & 34.47 & 42.1 & 0.71 & $48.69^{*} \pm 9.75$ & $0.38^{*} \pm 0.09$ & 0.53 \\
Quadratic & 'Barekat' & 15.64 & 26.63 & 0.78 & $8.58 \pm 5.71$ & $0.86 \pm 0.09$ & 0.83 \\
& 'Saraziri' & 14.05 & 23.86 & 0.81 & $3.84 \pm 5.24$ & $0.95 \pm 0.08$ & 0.87 \\
& 'Eraghi' & 11.69 & 21.12 & 0.61 & $10.81^{*} \pm 4.58$ & $0.79^{*} \pm 0.08$ & 0.85 \\
& 'Gavi' & 41.75 & 48.43 & 0.67 & $37.91^{*} \pm 11.81$ & $0.55^{*} \pm 0.11$ & 0.60 \\
& 'Barekat' & 15.65 & 26.89 & 0.79 & $9.1 \pm 5.72$ & $0.83 \pm 0.09$ & 0.82 \\
Curve & 'Saraziri' & 14.15 & 24.11 & 0.82 & $4.55 \pm 5.27$ & $0.93 \pm 0.08$ & 0.87 \\
& 'Eraghi' & 13.15 & 23.27 & 0.70 & $7.82 \pm 5.16$ & $0.86 \pm 0.08$ & 0.84 \\
& 'Gavi' & 34.24 & 42.06 & 0.76 & $42.65^{*} \pm 9.68$ & $0.44^{*} \pm 0.09$ & 0.59 \\
& 'Barekat' & 18.52 & 31.54 & 0.75 & $13.13 \pm 6.76$ & $0.78 \pm 0.11$ & 0.75 \\
& 'Saraziri' & 17.61 & 29.79 & 0.75 & $8.94 \pm 5.56$ & $0.86 \pm 0.10$ & 0.79 \\
& 'Eraghi' & 15.08 & 26.24 & 0.70 & $5.62 \pm 5.91$ & $0.92 \pm 0.10$ & 0.83 \\
& 'Gavi' & 33.97 & 41.74 & 0.72 & $48.82^{*} \pm 9.62$ & $0.37^{*} \pm 0.09$ & 0.53 \\
\hline
\end{tabular}

In all models, the function of the photoperiod has been a kind of piecewise. Regression coefficients $(\mathrm{a}, \mathrm{b})$ and correlation coefficient ( $\mathrm{r}$ ) that are related to the number of days from the observed and predicted emergence to the flowering stage have been presented. *For a coefficient, the significant difference is zero, and for b coefficient, the significant difference is 1 .

Tab. 4. Root mean square deviation (RMSD), variable coefficient (CV), R square $\left(\mathrm{R}^{2}\right)$ for the different descriptive model relationship between flowering rate with temperature and photoperiod in the four faba bean (Vicia faba L.) cultivars

\begin{tabular}{|c|c|c|c|c|c|c|c|}
\hline Temperature function & Cultivar & RMSD & $\mathrm{CV}$ & $\mathrm{R}^{2}$ & $\mathrm{a} \pm \mathrm{SE}$ & $\mathrm{b} \pm \mathrm{SE}$ & $\mathrm{r}$ \\
\hline \multirow{4}{*}{$\beta$} & 'Barekat' & 8.33 & 15.02 & 0.88 & $11.55^{*} \pm 3.04$ & $0.75^{*} \pm 0.05$ & 0.93 \\
\hline & 'Saraziri' & 7.55 & 13.55 & 0.91 & $9.56^{*} \pm 2.81$ & $0.79^{*} \pm 0.04$ & 0.94 \\
\hline & 'Eraghi' & 8.10 & 15.00 & 0.81 & $12.3^{*} 0 \pm 3.18$ & $0.74^{*} \pm 0.05$ & 0.91 \\
\hline & 'Gavi' & 11.22 & 14.19 & 0.89 & $14.8^{*} 9 \pm 3.17$ & $0.73^{*} \pm 0.03$ & 0.97 \\
\hline \multirow{4}{*}{ Quadratic } & 'Barekat' & 12.07 & 21.44 & 0.80 & $14.83^{*} \pm 4.41$ & $0.71^{*} \pm 0.07$ & 0.85 \\
\hline & 'Saraziri' & 10.60 & 18.82 & 0.83 & $11.63^{*} \pm 3.95$ & $0.77^{*} \pm 0.06$ & 0.89 \\
\hline & 'Eraghi' & 12.25 & 22.00 & 0.62 & $12.36^{*} \pm 4.80$ & $0.77^{*} \pm 0.08$ & 0.83 \\
\hline & ‘Gavi’ & 22.93 & 36.76 & 0.73 & $36.29^{*} \pm 8.47$ & $0.48^{*} \pm 0.08$ & 0.67 \\
\hline \multirow{4}{*}{ Piecewise } & 'Barekat' & 21.24 & 34.67 & 0.57 & $16.29^{*} \pm 7.76$ & $0.77 \pm 0.12$ & 0.70 \\
\hline & 'Saraziri' & 20.40 & 32.67 & 0.59 & $9.64 \pm 7.60$ & $0.93 \pm 0.12$ & 0.76 \\
\hline & 'Eraghi' & 19.23 & 31.63 & 0.45 & $8.53 \pm 7.54$ & $0.93 \pm 0.12$ & 0.76 \\
\hline & 'Gavi’ & 31.37 & 39.60 & 0.71 & $49.92^{*} \pm 8.88$ & $0.33^{*} \pm 0.09$ & 0.52 \\
\hline \multirow{4}{*}{ Curve } & 'Barekat' & 12.08 & 21.45 & 0.80 & $14.84^{*} \pm 4.41$ & $0.71^{*} \pm 0.07$ & 0.85 \\
\hline & 'Saraziri' & 10.18 & 18.01 & 0.83 & $11.09^{*} \pm 3.80$ & $0.79^{*} \pm 0.06$ & 0.90 \\
\hline & 'Eraghi' & 12.71 & 22.72 & 0.70 & $10.73^{*} \pm 4.98$ & $0.80 \pm 0.82$ & 0.83 \\
\hline & 'Gavi' & 29.09 & 37.03 & 0.76 & $43.27^{*} \pm 8.23$ & $0.40 \pm 0.79$ & 0.62 \\
\hline \multirow{4}{*}{ Saw tooth } & 'Barekat' & 19.34 & 32.47 & 0.75 & $10.90^{*} \pm 7.01$ & $0.84^{*} \pm 0.11$ & 0.76 \\
\hline & 'Saraziri' & 15.84 & 27.63 & 0.74 & $13.92^{*} \pm 5.90$ & $0.75^{*} \pm 0.09$ & 0.78 \\
\hline & 'Eraghi' & 14.59 & 25.59 & 0.70 & $7.93^{*} \pm 5.72$ & $0.87 \pm 0.09$ & 0.82 \\
\hline & 'Gavi' & 31.37 & 39.60 & 0.71 & $49.92^{*} \pm 8.88$ & $0.33^{*} \pm 0.09$ & 0.52 \\
\hline
\end{tabular}

In all models, the function of the photoperiod has been a kind of negative exponential. Regression coefficients (a,b) and correlation coefficient (r) that are related to the number of days from the observed and predicted emergence to the flowering stage has been presented. *For a coefficient, the significant difference is zero, and for $b$ coefficient, the significant difference is 1 .

we can point to simple linear regression equation (Ellis $e t$ al., 1988), exponent equation (Angus et al., 1981), logistic model (Horie, 1994), $\beta$-model (Yin et al., 1996), and Saw tooth-quadratic model (Soltani et al., 2006a). 

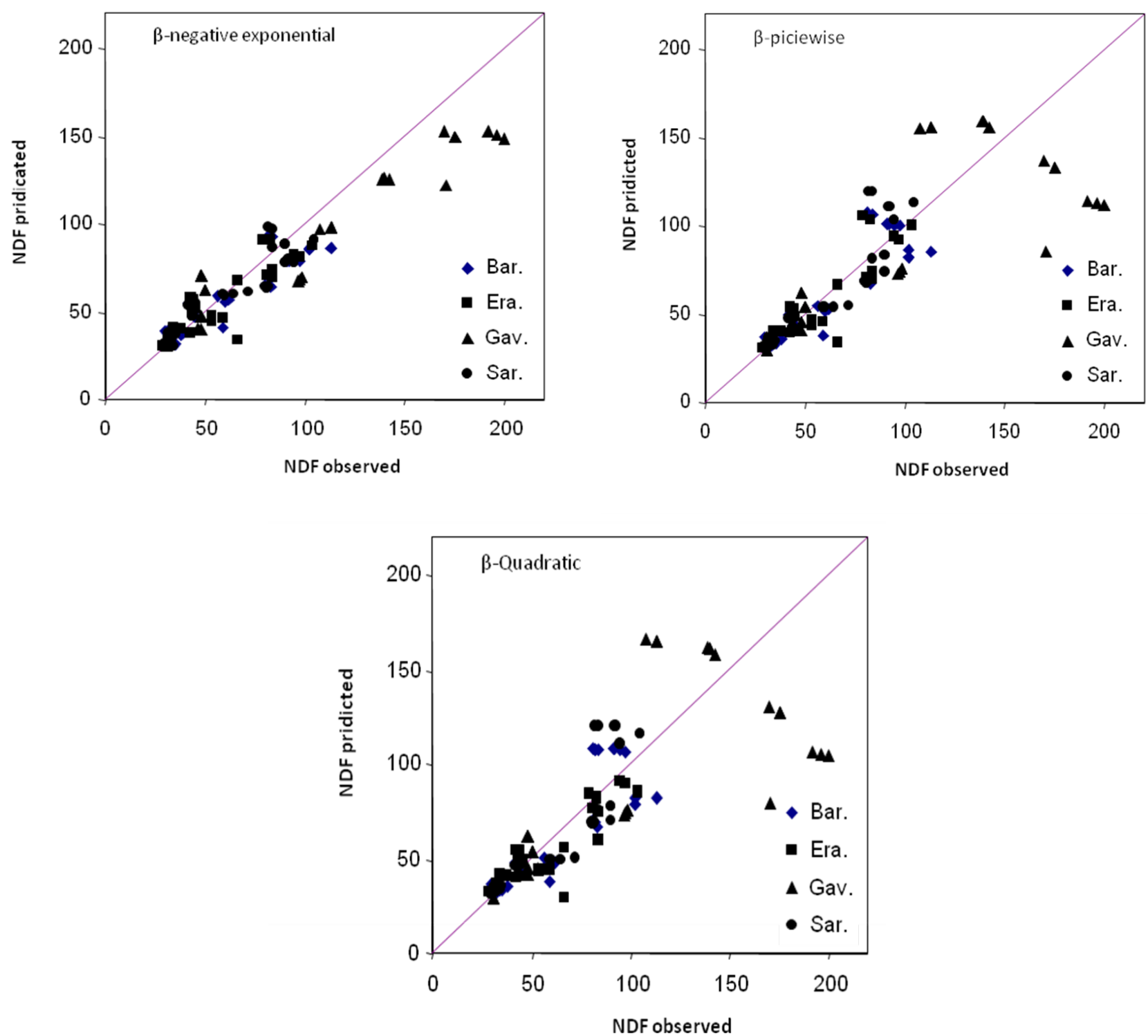

Fig. 1. Number of observed days from emergence to flowering, opposite its predicted in 'Barekat' (Bar), 'Eraghi' (Era), 'Gavi' (Gav), and 'Saraziri' (Sar) cultivars using the $\beta$-piecewise (B-S), $\beta$-quadratic, and $\beta$-negative exponential models

\section{Model parameters for the flowering stage}

The better model for 'Barekat,', 'Saraziri', and 'Eraghi' cultivars means that the $\beta$ temperature function in combination with the function of the piecewise photoperiod ( $\beta$-S model) calculated the base temperature in the flowering stage, -1 degrees centigrade for the three cultivars (Tab. 5). Also, the better model for 'Gavi', named $\beta$-negative exponent model, calculated the base temperature for its flowering stage, -1 degrees centigrade (Tab. 5). Soltani et al. (2006a), with the use of Saw tooth-quadratic model, reported the base temperature for all pea cultivars, 3.3 degrees centigrade. Madakadze (2001), with the use of the two variable linear regressions that had related the flowering rate to the temperature and the photoperiod, calculated and reported the base temperature for ten soybean cultivars with limited growth between 5.1 and 10 degrees centigrade. Optimum temperature for the flowering of 'Barekat,' 'Saraziri', and 'Eraghi' cultivars calculated by the $\beta$-piecewise model was somehow different because, with this model, the optimum temperature of flowering in 'Barekat', 'Saraziri', and 'Eraghi' cultivars were 28.3, 27.7, and 20.6 degrees centigrade, respectively. In addition, the optimum temperature for the flowering of 'Gavi' cultivar was with calculated $\beta$-negative exponent model 24.6 (Tab. 5). Ellis et al. (1988b) reported the optimum temperature for the flowering of 6 bean cultivars 19.9-26.5 degrees centigrade. Turpin et al. (2003) reported a minimum optimum temperature of 17 and 23 degrees centigrade for the winter and spring types of the bean, respectively. Ellis et al. (1988b) calculated the minimum and maximum optimum temperature for the whole cultivars of 20 and 33.1 degrees centigrade with the use of the saw tooth-quadratic model. The minimum days until the flowering stage in the preferred conditions of the temperature and photoperiod for the 'Barekat', 'Saraziri', and 'Eraghi' cultivars were 30.6, 29.2, and 35.9, respectively, with $\beta$-piecewise model. At 
Tab. 5 . Estimate of a fixed coefficient, base temperature ( $\mathrm{Tb}$ ), optimum temperature (To), ceiling temperature, the minimum number of days to flowering in optimum temperature and photoperiod (Fo), critical photoperiod (CPP), sensitive coefficient to photoperiod (PPsen) for flowering of the four faba bean (Vicia faba L.) cultivars with $\beta$-piecewise (B-S), $\beta$-quadratic, and $\beta$-negative exponential models

\begin{tabular}{ccccccccc}
\hline Temperature function & Cultivar & $\mathrm{a}$ & $\mathrm{Tb}$ & $\mathrm{To}$ & $\mathrm{Tc}$ & Fo & $\mathrm{CPP}$ & $\mathrm{PP}_{\text {Sen }}$ \\
\hline \multirow{3}{*}{$\mathrm{B}-\mathrm{S}$} & 'Barekat' & $0.25 \pm-0.72$ & $0 \pm-1$ & $3.53 \pm 28.3$ & 35 & $1.36 \pm 30.64$ & $0.17 \pm 15.81$ & $0.01 \pm-0.17$ \\
& 'Saraziri' & $0.19 \pm-0.97$ & $0 \pm-1$ & $1.79 \pm 27.69$ & 35 & $0.18 \pm 29.24$ & $0.34 \pm 16.05$ & $0.003 \pm-0.17$ \\
& 'Eraghi' & $0.28 \pm-0.85$ & $0 \pm-1$ & $1.16 \pm 20.63$ & 35 & $1.56 \pm 35.87$ & $0.20 \pm 14.54$ & $0 \pm-0.2$ \\
& 'Gavi' & $0.87 \pm-1.07$ & $6.18 \pm 3.99$ & $0.75 \pm 22.19$ & 35 & $1.37 \pm 27.8$ & $0.16 \pm 16.92$ & $0.004 \pm 0.16$ \\
\hline \multirow{5}{*}{ B-Q } & 'Barekat' & $0.26 \pm-0.71$ & $0 \pm-1$ & $2.47 \pm 25.75$ & 35 & $0.71 \pm 24.21$ & $0 \pm 21$ & $0.0002 \pm 0.008$ \\
& 'Saraziri' & $0.22 \pm-0.94$ & $0 \pm-1$ & $1.57 \pm / 25.83$ & 35 & $0.57 \pm 24.03$ & $0 \pm 21$ & $0.0002 \pm 0.009$ \\
& 'Eraghi' & $0.14 \pm 0.05$ & $0 \pm-1$ & $0 \pm 32$ & 35 & $0.56 \pm 28.95$ & $0.37 \pm 19.09$ & $0 \pm 0.01$ \\
\hline & 'Gavi' & $0.72 \pm 0.86$ & $5.78 \pm 4.92$ & $0.92 \pm 20.99$ & 35 & $1.37 \pm 26.66$ & $0 \pm 21$ & $0.00003 \pm 0.009$ \\
\hline \multirow{5}{*}{ B-NE } & 'Barekat' & $0.32 \pm-0.72$ & $0 \pm-1$ & $5.55 \pm 28.1$ & 35 & $1.61 \pm 31.77$ & $0.27 \pm 14.93$ & $0.04 \pm 0.35$ \\
& 'Saraziri' & $0.35 \pm-0.63$ & $0 \pm-1$ & $1.54 \pm 20.24$ & 35 & $1.64 \pm 35.08$ & $0.27 \pm 14.31$ & $0.05 \pm 0.32$ \\
& 'Eraghi' & $0.28 \pm-0.84$ & $0 \pm-1$ & $4.68 \pm 29.45$ & 35 & $2.21 \pm 31.99$ & $0.2 \pm 14.98$ & $0.03 \pm 0.39$ \\
& 'Gavi' & $0.62 \pm-2.45$ & $0 \pm-1$ & $2.17 \pm 24.58$ & 35 & $3.95 \pm 33.07$ & $0.33 \pm 15.33$ & $0.08 \pm 0.56$ \\
\hline
\end{tabular}

Ceiling temperature was constantly at 35 degrees

the same situation, the $\beta$-negative exponent model obtained an amount of 33.1 days for the 'Gavi' cultivar. Soltani et al. (2006a), using the saw tooth-quadratic model, calculated the photoperiod for pea cultivars (22.7-32.9 days). The ceiling photoperiod for 'Barekat,' 'Saraziri', and 'Eraghi' cultivars was 15.8, 16.1, and 14.5 hours, respectively, with the use of $\beta$-piecewise model. In addition, the ceiling photoperiod for the 'Gavi' cultivar was calculated 15.3 hours with the use of $\beta$-negative exponent model (Tab. 5). The sensitivity coefficient to the photoperiod for 'Barekat,' 'Saraziri', and 'Eraghi' cultivars with $\beta$-piecewise model was $0.17,-0.17$, and -0.20 , respectively, whereas that for 'Gavi' cultivar with the use of the $\beta$-negative exponent model was 0.56 (Tab. 5). Turpin et al. (2003) reported the base and ceiling photoperiod for bean flowering of 12.5 and 14 hours, respectively. Soltani et al. (2006a), with the use of the saw tooth-quadratic model, reported a ceiling photoperiod for pea cultivar of 20.8-22.2 hours. Using the same model, they also calculated the sensitivity coefficient to photoperiod for pea cultivars (0.008). Stutzel (1995a) reported that the photoperiod range necessary for the flowering of spring and fall bean cultivars also is 24 hours. In most bean cultivars, the flower initiation is included with lengthening of the day (Robertson et al., 2002b). Ellis et al. (1988) reported that long-day bean plants (16 hours' light), with night temperature of 13 degrees and day temperature of 24 degrees, have an early and faster flowering stage. Robertson et al. (2002a) compared the related parameters to photoperiod of 10 oat genotypes. and the ceiling photoperiod range in these 10 genotypes was small, but the critical photoperiod range was greater. Miralles et al. (2001) reported that for 2 oat cultivars, when photoperiod from 10.5 reaches 13.5 hours, the time interval of plantlet emergency until flowering decreases rapidly.
Research on the quality of the reaction to the photoperiod

According to the research on the necessary time for reaching the flowering stage in each sowing date and determining the most suitable photoperiod function for every cultivar, the reaction of different bean cultivars to the photoperiod was markedly different. So the photoperiod function of piecewise $(f(P P)=[1-(P P-C P P) \times P P S e n])$ was selected for 'Barekat', 'Saraziri', and 'Eraghi' cultivars as the better model. From the results, and as shown in Tab. 5 , the following equation was determined; for these cultivars, when the photoperiod reaches 10 hours, the flowering stops or the flowering rate will be zero([1 - (PP $\mathrm{CPP}) \times \mathrm{PPSen}]=0])$. Because with regard to the result of Tab. 5, the minimum photoperiod for the flowering of these cultivars was 9.9 hours $([1-(\mathrm{pp}-15.8) \times(-0.17)])$ $=0 \Rightarrow p p=9.9)$; therefore, the reaction of Barekar, 'Saraziri', and 'Eraghi' cultivars to the photoperiod is a kind of qualitative long-day reaction; the plant reaches the flowering stage where the photoperiod becomes more than the determined amount (in this examination, 10 hours). On the other hand, the photoperiod function with the negative exponent for the 'Gavi' cultivar was selected as a better model. $(f(P P)=[\exp (-P P S e n \times(c p p-p p)])$. Because the exponent function range is always a positive number $(f a: 1 R \rightarrow 1 R+)$, the exponent function range will never be a negative number or equal to zero. Therefore, the flowering reaction of the 'Gavi' cultivar to the photoperiod is a longday qualitative reaction. In a long-day qualitative reaction, the flowering rate does not reach zero at any photoperiod. The sowing dates in November, December, January, and February (Tab. 2) showed that, with delay in planting, the number of days from sprouting to the flowering stage of the 'Barekat' cultivar decreased despite a temperature decrease. As shown in Tab. 2, the number of days from 
sprouting to the flowering stage of these sowing dates was 111 (November), 105 (December), 84 (January), and 67 days (February). Therefore, it is clear that when the photoperiod does not reach the determined amount, the cultivated plants in these sowing dates remained in their vegetative state. Ellis et al. (1992) reported that those critical photoperiods that delay the flowering of different bean cultivars is more than 18 hours of the daily light. Besides, it was determined that the critical photoperiod (the maximum longest photoperiod that delays the flowering stage) for the different bean genotype is not the same, except bean cultivars that flower sooner; in other bean cultivars, the flower initiation occurs with high temperature and long day. On the other hand, the complete development of flower initiation requires long days. In a temperature higher than 14 degrees centigrade, and especially higher than 23 degrees centigrade, a kind of inhibition happens in the bean's flower initiation. Temperature lower than 10 degrees centigrade can be effective in the bean's flower initiation. The plant also can receive such low temperature during the fetal period on the base plant (Evans, 1959). Hadley et al. (1984) also reported that most of the bean genotypes are sensitive to the photoperiod and reach the flowering stage during long days. In most oat genotypes, the ceiling photoperiod was more than 10 to 16 hours of day light (Roberts et al., 2002). Soltani et al. (2006a) reported that the flowering reaction of the pea cultivar to the photoperiod is a kind of qualitative or compulsorily long day, whereas previously, the reaction to the photoperiod in the pea had been reported as a qualitative long-day reaction (Verghis et al., 1999).

\section{The necessary biological day for the different growth stages}

Calculating the biological number of days for sprouting stages and flowering was done with the growth rate model and the following model:

$$
C B D=\sum_{i=1}^{n}(f(T) \cdot f(P P))
$$

Where CBD is the accumulation of the biological day for considerate growth stage, $f(T)$ is temperature factor, $f(P P)$ is the photoperiod factor, and $n$ is the number of calendar days from a growth stage to another stage. For calculating the biological number of days, the equation (1) was used from the daily dates of maximum and minimum temperature and photoperiod. The amount of temperature factor was determined in the following equation, the better function, $\beta$ (refer to the results and discussion):

$$
f(T)=\left[\left(\frac{\left(T-T_{b}\right)}{\left(T_{o}-T_{b}\right)} \times \frac{\left(T_{c}-T\right)}{\left(T_{c}-T_{b}\right)}\right)^{\left(\frac{\left(T_{c}-T_{o}\right)}{\left(T_{o}-T_{b}\right)}\right)}\right]^{\alpha}
$$

The photoperiod factor with regard to better function of piecewise (3) for 'Barekat', 'Saraziri', and 'Eraghi' culti- vars and the negative exponent (4) for 'Gavi' cultivar also were calculated using the following equations:

$$
\begin{aligned}
& f(P P)=[1-(P P-C P P) \times P P S e n] \quad \mathrm{Eq}(3) \\
& f(P P)=[\exp (-P P \operatorname{Sen} \times(c p p-p p)] \quad \mathrm{Eq}(4)
\end{aligned}
$$

The product of the amount of temperature and photoperiod factors for each day was calculated; then, the days between the two growth stages were added and considered as the biological number of days for that stage, and its amount in every place and sowing date is fixed theoretically. Because sprouting stage does not react to the photoperiod, the amount of sensitivity factor to the photoperiod $f(P P)$ for this stage was considered to be 1 . Also, the biological number of days from the pudding stage to the physiological maturation was calculated without the reaction of this stage to the photoperiod $(f(P P)=1)$. In this experiment, the sprouting stage to the flowering stage and the flowering stage to the physiological maturation from the cardinal temperature and the biological number of days required for reaching the growth stage were calculated (Tab. 6 and 7) that in bean phonological growth modeling, in reaction to a wide range the temperature and biologic day's number are used. As shown in Tab. 6, there was a significant difference in the biological number of days from planting to the sprouting of the bean cultivars. The comparison of the mean of the cultivars from the aspect of the biological number of days to sprouting showed that the 'Gavi' cultivar with 6.9 day's needs less biological number of days in comparison with other cultivars that their biological number of day in sowing stage to sprouting stage were between 8.2 and 8.9. Also, from the comparison of the results of the mean biological days from sprouting to flowering, a significant difference was observed between the bean cultivars so that, in this stage, the 'Eraghi' cultivar with 32.1 days has the maximum biological days, and the 'Barekat', 'Saraziri', and 'Eraghi' cultivars with 21.3 to 24.9 days have the minimum biological days (Tab. 6). In addition, the comparison of the mean number of days from flowering to pudding for the bean cultivar showed that the maximum biological days in this stage, with 15.2 days, was related to the 'Eraghi' cultivar, and the least, with 7.7 to 9.5 days, was related to the 'Gavi' and 'Saraziri' cultivars; however, , there was no significant difference between the cultivars in terms of the comparison of the mean biological number of days from pudding to seed filling. Thus, the biological number of days needed for this stage in the different cultivars was variable between 9.9 and 15.1 (Tab. 6). Also, the comparison of the results showed that with attention to the biological number of days from seed filling to physiological maturation, there is a significant difference between the bean cultivars so that the maximum biological days for reaching this stage, with 23.7 to 24.2 days, was related to the 'Barekat,' 'Saraziri', and 'Eraghi' cultivars, and the least, with 15.6 days, was related to the 'Gavi' cultivar (Tab. 6). At the end, in comparing the mean biological days between the physiological maturation and complete plant maturation, it was determined that there was no significant difference between the bean cultivars, and the re- 
206

Tab. 6. Average of necessary biological number of days of the four faba bean (Vicia faba L.) cultivars in the development stages

\begin{tabular}{cccccccc}
\hline Cultivar & PE & EF & FP & PS & SM & MR & PM \\
\hline 'Barekat' & $8.5 \mathrm{a}$ & $24.1 \mathrm{~b}$ & $10.6 \mathrm{ab}$ & $14.4 \mathrm{a}$ & $24.2 \mathrm{a}$ & 6.5 & $88.1 \mathrm{~b}$ \\
'Saraziri' & $8.2 \mathrm{a}$ & $21.9 \mathrm{~b}$ & $9.5 \mathrm{~b}$ & $14.6 \mathrm{a}$ & $23.7 \mathrm{a}$ & 7.0 & $84.9 \mathrm{~b}$ \\
'Eraghi' & $8.9 \mathrm{a}$ & $32.1 \mathrm{a}$ & $15.2 \mathrm{a}$ & $15.1 \mathrm{a}$ & $23.0 \mathrm{a}$ & 6.4 & $100.7 \mathrm{a}$ \\
'Gavi' & $6.5 \mathrm{~b}$ & $21.3 \mathrm{~b}$ & $7.7 \mathrm{~b}$ & $9.9 \mathrm{a}$ & $15.6 \mathrm{~b}$ & 5.9 & $66.9 \mathrm{c}$ \\
\hline
\end{tabular}

$\mathrm{PE}=$ planting until emergence, $\mathrm{EF}=$ emergence until flowering, $\mathrm{FP}=$ flowering until pudding, $\mathrm{PS}=$ pudding until seed filling, $\mathrm{SM}=$ seed filling until maturation, $\mathrm{MR}=$ maturation until complete maturation, $\mathrm{PM}=$ planting until maturation

Tab. 7 . Maximum, minimum, and average development in the different stages in different sowing dates of the four faba bean (Vicia faba L.) cultivars

\begin{tabular}{ccccc}
\hline Cultivar & Variable & Max & Min & Average \\
\hline \multirow{4}{*}{ 'Barekat' } & FP & 17 & 3 & 10.6 \\
& PS & 21 & 5.5 & 9.5 \\
& SM & 34 & 15 & 24.2 \\
& MR & 10 & 3 & 6.5 \\
\hline \multirow{6}{*}{ 'Saraziri' } & FP & 13 & 4 & 9.5 \\
& PS & 23 & 5.5 & 9.6 \\
& SM & 29 & 15 & 23.7 \\
& MR & 12 & 3 & 7 \\
\hline \multirow{3}{*}{ 'Eraghi' } & FP & 28 & 6 & 15.2 \\
& PS & 22 & 5.8 & 9.9 \\
& SM & 28 & 15 & 23 \\
& MR & 12 & 3 & 6.4 \\
\hline \multirow{6}{*}{ 'Gavi' } & FP & 20 & 5 & 7.7 \\
& PS & 16 & 6 & 9.9 \\
& SM & 19 & 8 & 15.6 \\
\hline
\end{tabular}

$\mathrm{FP}=$ flowering until pudding, $\mathrm{PS}=$ pudding until seed filling, $\mathrm{SM}=$ seed filling until maturation, $\mathrm{MR}=$ maturation until complete maturation

quired biological number of days in this stage is between 5.9 and 7.1 days. From cultivation to complete maturation, 66.9 to 100.7 biological days are needed for the different cultivars. Among them, the 'Gavi' cultivar, with 66.9 days, had the least biological number of days and was the earliest to mature, and the 'Eraghi' cultivar, with 100.7 days, was the latest to mature (Tab. 6). Similar studies were done on the pea by Soltani et al. (2006a). In their conclusions, the jam cultivar with 62.2 biological days was the earliest to mature, and the 90-96c cultivar, with 71.9 biological days, was the latest to mature. Jame et al. (2004), in similar studies on wild millet, showed that the phonological stages in biological days are formed in the following manner: 1.9 days from cultivation to sprouting, 4.9 biological days from plant emergence to flower bud initiation, 4 biological days from flowering to seed formation, 4.1 biological days from heading to flowering, 3.5 biological days from flowering to seed formation, and 4.1 biological days from seed formation to maturation end. Horie (1994), with a study on Echinochlon crus-galli, showed the phonological stage based on the temperature day in the following manner: 1.9 temperature days from planting to sprouting, 4.4 temperature days from sprouting to flowering bud initiation, 8.8 temperature days from flower bud initiation to heading, 0.8 temperature days from heading to flowering, 4.8 temperature days from flowering to the end of flowering, and 1.3 temperature days from the end of flowering to seed formation.

\section{References}

Angus JF, Cunningham RB, Moncur MW, Mackenzie DH (1981). Phase development in field crops. I. Thermal response in the seedling phase. Field Crop Res 3:361-378.

Birch CJ, Hammer GL, Rickert KG (1998).Temperature and photoperiod sensitivity of development in five cultivars of maize (Zea mays L.) from emergence to tassel initiation. Field Crops Res 55:93-107.

Ellis RH, Roberts EH, Summerfield RJ (1988). Photo-thermal Time for Flowering in Faba Bean (Viciafaba) and the Analysis of Potential Vernalization. Annals of Botany 35:455-463

Ellis RH, Summerfield RJ, Edmeaes GO, Roberts EH (1990). Flowering in faba bean: genotypic differences in photoperiod sensitivity, similarities in temperature sensitivity, and implications for screening germplasm. Ann Botany 65:129138.

Ellis RH, Summerfield RJ, Edmeaes GO, Roberts EH (1992). Photo-thermal time for flowering in faba bean (Vicia faba) and the analysis of potential vernalization. Ann Botany 35:455-463.

Evans LT (1959). Environmental control of flowering in Vicia faba L. Ann Botany 23:521-546.

Farre M, Robertson J, Walton GH, Asseng S (2002). Simulating phonology and yield response of canola to sowing date in Western Australia using the APSIM model. Australian J Exp Agric 53:1155-1164.

Fehr WR, Cavinees CE (1980). Stage of soybean development. Iowa Crop Exp Serr Agric Home Econ Exp Stn Spc Rep 80.

Grimm SS, Jones JW, Boote KJ, Herzog DC (1994). Modeling the occurrence of reproductive stages after flowering for four soybean cultivars. Agron J 86:31-38.

Grimm SS, Jones JW, Boote KJ, Heskerth DJ(1993). Parameter estimation for predicting flowering date of soybean cultivars. Crop Sci 33:137-144.

Hadley P, Roberts EH, Summerfield RJ, Minchin FR (1984). Effects of temperature and photoperiod on flowering in soybean (Glycine $\max$ (L.) Merrill.): a quantitative model. Ann Bot 53:669-681.

Hammer GL, Goyne PJ, Woodruff DR (1996). Phonology of sunflower cultivars. III. Models for prediction in field environments. Aust J Agric Res 33:263-274.

Horie T (1994). Crop ontogeny and development, p. 153-180. In: Boote KJ, Bennett JM, Sinclair TR, Paulsen GM (Eds.). Physiology and determination of crop yield. ASA, CSSA, 
and SSSA, Madison, USA.

Jame YW, Cutforth HW (2004). Simulating the effect of temperature and sowing depth on germination and emergence of spring wheat. Agric For Meteorol 124:207218.

Khajehpour MR (1998). The role of temperature and photoperiod in selected crop sowing date, p. 35-55. In: Abstracts of key-note papers. $5^{\text {th }}$ Iranian Congress of Crop Production and Plant Breeding.

Madakadze IC, Prithiviraj B, Stewart KA, Peterson PR, Coulman BE, Smith DL (2001).Variation in base temperatures for germination in warm season grasses. Seed Sci Technol 29:31-38.

Miralles DJ, Ferro BC, Slafer GA (2001). Development responses to sowing date in wheat, barley and rapeseed. Field Crops Res 71:211-223.

Roberts EH, Summerfield RJ, Ellis RH, Stewart KA (2002). Photo-thermal time for flowering in lentils and the analysis of potential vernalization responses. Ann Bot 61:29-39.

Robertson MJ, Carberry PS, Huth NI, Turpin JE, Probert ME, Poulton PL, Bell M, Wright GC, Yeates SJ, Brhnsmead RB (2002a). Simulation of growth and development of diverse legume species in APSIM. Aust J Agric Res 53:429-446.

Robertson MJ, Watkinson AR, Kirkegaard JA, Holland JF, Potter TD, Burton W, Walton GH, Moot DJ, Wratten N,Farre I, Asseng S (2002b). Environmental and genotypic control of time to flowering in canola and Indian mustard. Aust J Agric Sci 53:793-809.

Soltani A (1998). Application of SAS in statistical analysis, Mashhad University, $166 \mathrm{p}$.
Soltani A, Hammer GL, Torabi B, Kobertson MJ, Zeinali E (2006a). Modeling. Chickpea: growth and development: Phonological development. Field Crops Res 99:1-13.

Soltani A, Robertson MJ, Torabi B, Yousefidaz M, Sarparast R (2006b). Modeling seedling emergence in chickpea as in fluency by temperature and sowing depth. Agric For Meteorol 138:156-167.

Stutzel H (1995a). A simple model for simulation of growth and development in faba beans (Vicia faba L.): I. Model description. Eur J Agron 4:175-185.

Stutzel H (1995b). A simple model for simulation of growth and development in faba beans (Vicia faba L.): II. Model evaluation and application for the assessment of sowing date effects. Eur J Agron 4:187-195.

Turpin JE, Robertson MJ, Haire C, Bellotti WD, Moore A, Rose D (2003) I. Simulating fababean development, growth and yield in Australia. Aust J Agric Res 54:39-52.

Turpin JE, Robertson MJ, Hillcoat NS, Herridage D, Dage E (2002). Faba bean (Vicia faba) in Australia's northern grains belt: canopy development, biomass and nitrogen accumulation and partitioning. Auh J Agric 53:227-237.

Verghis TI, Mckenzie BA, Hill GD(1999). Phenological development of chickpea in Canterbury, New Zealand. New Zealand J Crop Hort Sci 27(3):249-256.

Yin X, Kropff MJ, Nakagawa H, Horie T, Goudriaan JA (1997). Model temperature for photo thermal responses of flowering in rice. I. Model evaluation. Field Crop Res 51:189-200.

Yin X, Kropff MJ, Ellis RH (1996). Rice flowering in response to diurnal temperature amplitude. Field Crops Res 48:1-9. 